\title{
Genres, User Attitude and Prospects for Learning through Video on the WWW
}

\author{
Dr. Piet Kommers \\ Assistant Professor, Faculty of Educational Science and Technology, U. of Twente, Netherlands \\ kommers@edte.utwente.nl
}

\begin{abstract}
Building upon the notion that TV and video programis will be accessible via the web, there is the question if and how it can bring added value for education. How will these two genres (working on internet versus relaxing on the sofa) go together. From a post-modern point of view, the mass media like TV, contribute to the supposed mechanism of 'social constructionism'. However the program makers have a large control over the underlying message that is articulated, whereas Constructionism for learning is the more conscious process by which students 'build' new knowledge through experimentation and conceptualization.
\end{abstract}

\section{Introduction}

The idea of 'one-click' learning following the eshopping model is not likely to be successful; Learning demands longer-term interactions (or better: negotiations) with teachers and co-students about meanings, hidden mechanisms and strategies. The question is then how interactive video on demand will work out for the more conceptually complex learning domains. Research on the effects of simulation-based studying http://citeseer.nj.nec.com/30314.html reveals that simulation program as a learning tool has limited transfer to the average situation that needs this particular knowledge. Schär, Schluep, Schierz and Krueger demonstrate that the interaction mode is the critical factor in the success/failure of learning systems http://imej.wfu.edu/articles/2000/1/03/index.asp\#4. Its lesson for the use of video on the Web is that visualizations and interactions do not guarantee learning.

\section{Goal of the Discussion}

We might say that learning is exactly the growing capacity to generate what cannot be seen anyway. The continuous need for ever more flexible, quicker and less cannot be explored enough is the perceived discrepancy between entertainment and study that might obstruct users to learn from video in web applications. A classical view expensive media and networks for learning communities brings us to the added value of full video via the www: Bollozos (1997). In order to make a fair prediction in this direction, a number of orientations should be made.

1)The technology to enable and disseminate the needed infrastructure. Just like the early pioneering in educational computing, here we initially rely on the larger forces in the consumer market generating new opportunities for commercials and marketing; The higher its general economical impact: the more any educational side effects will come through: Hollar (1997) and Sagan (1997). .

2)The content providers like publishers, universities, branch organizations (for industrial and on-the-job training) need to manifest a new mutual relation. They realize that content in itself like books, video and even interactive programs do not necessarily bring its recipients to learning. Learning communities as cultural and social groups with a common learning need get more impact. Even universities understand that their future role depends on maintaining their alumni and playing a sustaining role in the life-long learning of former students; the certificate is no longer the single passport for expertise and qualified jobs for life.

3)The attitudes of intellectuals and employees towards information 'services' like broadcast programs and conferences are as modes of 'learning experiences' rather than 'information access'. This trend is in line with the recent development of learning paradigms such as 'collaborative', 'project-oriented', 'constructivistic' and 'cognitive apprenticeship'.

4)The status of 'learning' in itself undergoes an evolution as learning is almost integrated with working, entertainment and leisure time; Citizens who are in the position to travel, specialize in hobbies and cultural activities will spend a large part of their useage to "change themselves' and to experience immersive emotions as can be seen in reality $\mathrm{TV}$, risky sports and travels through fictitious landscapes created by VR.

It is this more intertwined combination of factors that will decide upon the speed and the amount of penetration of video on the web. One element that is to see the ultimate learning attitude as one of optimal attention, analytic and highly active. In this respect the "TV meets the Web" would have a detrimental effect on 
the students' learning if it generates the typical mood of 'divertissement', which might be called 'learning by forgetting'. Interaction as a highly desired property of new media like hypermedia, simulations and VR seems to have an inherent value for those who already realized in the early eighties that receiving information whether on a $\mathrm{TV}$ and through a www interface is only a tiny step in the facilitation of meaningful learning. Strom (1997) and Miles (1998). The main question has migrated from "Who has access and who doesn't?" into "Who has interest and who hasn't?" Feinleib (1999).

\section{Directions for Solutions}

Given the new opportunities for learning, it becomes a key question if and how persons are willing to make learning existential; to what extent do I want to change myself in order to accommodate the wider horizon in tolerance, multiculturalism and participation in ecology (both in the moral, ethnic and aesthetic senses). How "Video on the Web" will finally serve this wider goal is hard to answer. We are just in the stage of early experiments and still highly conceptual. Videoconference via the WWW will bring us a more realistic understanding of how body language extends communication over the highly cryptic email correspondence. The moment that we can flounder through virtual streets, and theatres it will 1 become more clear what can still be offered by normal broadcast video on demand. Such ultimate visuals could provoke similar feelings for conventional media as browsing through a photo or video album of yesterday.

\section{Directions for Solutions}

The time that project-oriented learning was a relief from one's individual responsibility is far behind; Teachers may start to show the more successful cases of previous years, and the learning group is often seen as an enterprise, competing with other groups. But will students suffer from over ambition and time stress.

Two directions for solutions will be brought forward: a) On-site learning communities should keep a high degree of informality with only a mature amount of competition and sufficient super-ordinate goals. b)If this is not affordable because of an over-stressed grading system, the student should find and relax in external WWW-based communication with students who belong to a different institute.

Though the first solution is inherently better, it might be inevitable to fall back on the second alternative. Here the communication serves a more emotional and personal function like consolation and regaining self-confidence. It is the more overall reflection on the link between studying and life itself that counts, and that is hardly reflected in the institutional context. Besides the direct learning community with students from the same institute, it seems beneficial to join the larger www-based learning communities for the sake of existential support without any threat of repercussions in one's own institute.

An adjacent aspect is the teachers' learning network that should be apart from their employer or supervisor. It should lead to real partnerships between teachers. Here the importance is to have a low-threshold consultancy mechanism for external peer review and sharing experiences. Teachnet and the 21 st Century Teachers Network (21CT) are examples. However, these still have a large emphasis on the provision of information. The community aspects still have to be worked out. The student and teacher network may have a lot in common than realised.

\section{Conclusion}

The integration of TV and the Internet will pose many social questions and pedagogical problems while it rolls out into education. How we answer the former will be critical to how we solve the latter.

\section{References}

1. Bollozos, s. \& Co. (1997). Webcasting. Push technology. hutp://userwww.sfsu.edu/ sbollozol

2. Feinleib, D. (1999). The inside story of Interactive TV and Microsoft WebTV for Windows. CA: Academic Press, San Diego.

3. Hollar, M.J. (1997). Webcasting on the Internet. http://members.aol.com/mikehollar/Webcasting.html 4. Miles. P. (1998). Guide to Webcasting. The Complete Guide to Broadcasting on the Web. New York: John Wiley \& Sons. 5. Sagan, P. (1997). Webcasting. Managing all media means mastering new media.

http://www medialink.com/webcast/foreword.hum! 6. Strom, D. (1997). Push media. Examining the latest crop of personalised web publishing techniques.

http://www. webreview.com/96/12/13/feature/index.html 